\title{
Mitochondria-Rich Cells: A Novel Type of Concealed Cell in the Small Intestine of Chinese Soft-Shelled Turtles (Pelodiscus Sinensis)
}

\author{
Waseem Ali Vistro, Yifei Liu, Mengdi Xu, Ping Yang, Abdul Haseeb $₫$, Yufei Huang, Xuebing Bai, \\ Liang Yu, Noor Samad Gandahi, Imran Tarique and Qiusheng Chen * $\mathbb{D}$ \\ MOE Joint International Research Laboratory of Animal Health and Food Safety, College of Veterinary Medicine, \\ Nanjing Agricultural University, Nanjing 210095, Jiangsu, China; 2017207039@njau.edu.cn (W.A.V.); \\ 2017807120@njau.edu.cn (Y.L.); 2017107004@njau.edu.cn (M.X.); yangping@njau.edu.cn (P.Y.); \\ 2016207037@njau.edu.cn (A.H.); 2017207007@njau.edu.cn (Y.H.); 2016107003@njau.edu.cn (X.B.); \\ 2016107004@njau.edu.cn (L.Y.); 2017207040@njau.edu.cn (N.S.G.); samoo_imran88@hotmail.com (I.T.) \\ * Correspondence: Chenqsh305@njau.edu.cn; Tel.: +86-25-84395305
}

Received: 27 August 2019; Accepted: 20 September 2019; Published: 24 September 2019

check for updates

\begin{abstract}
Although some studies have been conducted over the past few decades, the existence of mitochondria-rich cells (MRCs) in reptiles is still obscure. This is the first study to uncover the presence of MRCs in the small intestine of Chinese soft-shelled turtles. In this study, we investigated the ultrastructural characteristics of MRCs and the secretion of different ion transport proteins in the small intestine of Pelodiscus sinensis. Transmission electron microscopy revealed that the ultrastructural features of MRCs are clearly different from those of other cells. The cytoplasmic density of MRCs was higher than absorptive epithelial cells (AECs) and goblet cells (GCs). MRCs possessed abundant heterogeneous mitochondria and an extensive tubular system in the cytoplasm, however, the AECs and GCs completely lacked a tubular system. Statistical analysis showed that the diameter and quantification of mitochondria were highly significant in MRCs. Mitochondrial vacuolization and despoiled mitochondria were closely associated with autophagosomes in MRCs. The multivesicular bodies (MVBs) and the exosome secretion pathway were observed in MRCs. Immunohistochemical staining of ion transport proteins indicated positive immunoreactivity of $\mathrm{Na}^{+} / \mathrm{K}^{+}$-ATPase (NKA) and $\mathrm{Na}^{+} / \mathrm{K}^{+} / 2 \mathrm{Cl}^{-}$cotransporter (NKCC) at the basal region of the mucosal surface. Likewise, the immunofluorescence staining results showed a strong positive localization of NKA, NKCC, and carbonic anhydrase (CA) at the basal and apical region of the mucosal surface of small intestine. Our findings suggest that MRCs provide support and regulate cellular ions for intestinal homeostasis and provide energy for cellular quality control in intestine.
\end{abstract}

Keywords: MRC; ultrastructure; $\mathrm{Na}^{+} / \mathrm{K}^{+}$-ATPase; $\mathrm{Na}^{+} / \mathrm{K}^{+} / 2 \mathrm{Cl}^{-}$cotransporter; carbonic anhydrase; small intestine; Chinese soft-shelled turtle

\section{Introduction}

The digestive system of reptiles consists of the same arrangement of digestive organs as the arrangement present in other higher vertebrates, from mouth to cloaca [1]. The reptilian small intestine is highly convoluted, and its surface is varied (longitudinal and transverse folds) among different groups, such as snakes and Nile monitors [2]. The small intestinal epithelial cells perform two essential functions, namely, the secretion and absorption of electrolytes (sodium, potassium, and chloride) and the movement of net fluid across the gastrointestinal epithelium, which is primarily the result of the active transport of different ions [3]. 
The lower intestinal epithelium is lined with simple columnar cells that contain cilia on their apical surface, and these cells are also known as dark cells or brush cells [4]. Some of these special 'dark cells' or 'brush cells' are classified as MRCs. MRCs are one of the most important epithelial cell types observed in the lower intestine of chickens and are located in the upper part of the mucosal folds. Localization of MRCs mainly has been reported in gills, kidney, intestine, and yolk-sac membrane of fish [5-7], as well as in chicken intestines [8]. The intestinal epithelium of the Chinese soft-shelled turtle is composed of AECs, GCs, intraepithelial lymphocytes (IELs), and plasma cells [9], however, to date, these MRCs have never been observed in the intestines of reptiles.

Keys and Willmer were the first to explain the role of chloride cells in the secretion of $\mathrm{Cl}^{-}$ions [10]. The function of these cells is not limited to the secretion of chlorine $\left(\mathrm{Cl}^{-}\right)$; these cells also participate in the bidirectional transportation of many other ions, and it would be more suitable to refer to chloride cells as MRCs [11]. MRCs are a functional unit that regulate the ions in the teleost gill epithelium. These cells are morphologically characterized by numerous mitochondria with high electron density and contain numerous tubular systems in their cytoplasm [12]. Another morphological differentiation of MRCs is the development of multicellular complexes organized with adjacent accessory cells [11]. MRCs are the primary place for the active transport of ions in bronchial epithelial cells, and these cells secrete ions in seawater-adapted (SW-adapted) fish and in freshwater-adapted (FW-adapted) fish [13-15]. Certainly, amphibian skin is a heterogeneous epithelium, with MRCs scattered in the superficial layer among the bulk of the principal cells [16]. MRCs may also play an important role in acid-base regulation $[17,18]$. In addition, several environmental conditions, such as high temperature and high levels of organic matter, favor the occasional development of nitrite $\left(\mathrm{NO}_{2}{ }^{2-}\right)$ in the Amazonian environment and, in fish culture systems, this energetic mechanism involves $\mathrm{NO}_{2}{ }^{2-}$ uptake by the MRCs in the gill [19]. MRCs in the kidney tubules and gills are the primary cells responsible for ion transport. These cells contain large quantities of $\mathrm{Na}^{+} / \mathrm{K}^{+}$-ATPase (NKA), which creates a driving force for ion uptake from the water by the lumen of renal tubules in the kidney and gills [20].

Several authors have reported that MRCs possess the cooperative action of different ion transport proteins, namely, NKA and $\mathrm{Na}^{+} / \mathrm{K}^{+} / 2 \mathrm{Cl}^{-}$cotransporter (NKCC) [21]. Immunological localization studies have verified that NKA and NKCC are present at the basal region, and carbonic anhydrase (CA) is associated with the apical region with a tubular system of MRCs [22]. NKA is a widespread membrane-bound enzyme, which dynamically maintains the sodium potassium pump in animal cells. This protein is essential not only for the maintenance of intracellular homeostasis but also for impelling power for water and ion transport in the fish gills [23]. Fluctuation, like the high and low activity of the NKA pump, facilitates the absorption of nutrients within the small intestine [24]. NKA maintains low intracellular $\mathrm{Na}^{+}$and high extracellular $\mathrm{K}^{+}$concentrations, and NKCC mediates the entry of $\mathrm{Na}^{+}$and $\mathrm{Cl}^{-}$into the cellular compartment along the electrochemical gradient provided by NKA [25]. The $\mathrm{Na}^{+}$gradient is used to transport $\mathrm{Na}^{+}, \mathrm{K}^{+}$and $2 \mathrm{Cl}^{-}$into the cell through a basolateral NKCC, and $\mathrm{Cl}^{-}$then exits the cells along an electrical gradient through apical $\mathrm{Cl}^{-}$channels [26]. CA is widely present in the intestine. Its physiological role is the absorption of salt, water, and acid-base homeostasis in the intestine [27], however, all of the above findings were observed in fish, avian, and amphibian species and there is no clear functional information related to MRCs in the small intestine of reptiles. Chinese soft-shelled turtle is one of the most nutritional and pharmacological worthy animals in China.

Therefore, the objective of this study is to investigate the possible morphological relationship and the ultrastructural characteristics of MRCs, as well as the secretion of different ion transport proteins by MRCs, in the small intestine of Chinese soft-shelled turtles.

\section{Materials and Methods}

\subsection{Animals and Tissue Blocks Preparation}

For the present study, ten mature (4-5 years) old, Chinese soft-shelled turtles (Pelodiscus sinensis) were purchased from an aquatic Nanjing farm, Jiangsu Province, China. The turtles were anaesthetized 
by intraperitoneal injection of sodium pentobarbital $(20 \mathrm{mg} / \mathrm{animal})$ and then killed by neck dislocation. The small intestine specimens were obtained quickly and fixed for different experimental processes (details blow). The process of sampling was approved by the college of Veterinary Medicine of Nanjing Agricultural University. The study procedure was approved by the Science and Technology Agency of Jiangsu Province (Approval ID: SYXK (SU) 2010-0005). All processes with turtles were performed according to the Animal Research Institute Ethics Committee guidelines of Nanjing Agricultural University, China.

\subsection{Periodic Acid Schiff (PAS) Staining}

The fixed intestinal tissue slides were dehydrated with an alcohol grading sequence from $75-100 \%$, with the samples incubated in each grade for 2 minutes and cleared in xylene for 10 minutes. Then, the tissue slides were incubated in periodic acid ( $5 \mathrm{~g} / \mathrm{L}$ of water) for 5 minutes, rinsed in lukewarm water for 10 minutes, and stained in Coleman's Schiff reagent for 10 minutes, and then in hematoxylin for a few seconds. The tissue slides were examined with an electron microscope (BX50; Olympus, Tokyo, Japan), and images of the tissue slides were taken with an air-conditioned control coupled apparatus camera (DP72; Olympus through Cell Sens software, Nanjing China).

\subsection{Transmission Electron Microscopy (TEM)}

After tissue sample collection, the tissues were cut into small pieces and immersed in $2.5 \%$ glutaraldehyde fixative in $0.1 \mathrm{M}$ phosphate buffered saline (PBS) at $4{ }^{\circ} \mathrm{C}$ for 24 hours. The samples were post fixed in $1 \%(\mathrm{w} / \mathrm{v})$ osmium tetroxide and washed in PBS three times. Dehydration was carried out with a graded series of ethanol $(75-100 \%)$. Then, the samples were soaked in propylene oxide and embedded in Araldite. Ultrathin sections of selected areas were cut and mounted on Formvar-coated grids and stained with uranyl acetate and lead citrate for 20 minutes per step. The ultrastructure of the small intestine was viewed by a transmission electron microscope (Hitachi H-7650; Hitachi high-technologies Corporation, Tokyo, Japan).

\subsection{Immunohistochemistry (IHC)}

A standard staining immunohistochemistry protocol for MRCs was performed according to previous studies [12]. Small intestinal tissue slides were deparaffinized in xylene two times each, for ten minutes. All slides were incubated in a graded series of ethanol (75-100\%) for two minutes per grade. Antigenic sites were exposed by boiling for five minutes in 30\% sodium citrate and then rinsed three times in phosphate buffered saline (PBS). Tissue expression was determined using a rabbit anti-NKA antibody (1:100) (Wuhan Xavier Biotechnology Co., Ltd, Wuhan, China). All sections were stored at $4{ }^{\circ} \mathrm{C}$ for one night. The next day, we used goat anti-rabbit IgG (SABC; Bio-sharp Biotechnology Co., Wuhan, China as the secondary antibody. Sections were colored with DAB (Diaminobenzidine) (Boster, Sigma Chemical Co., St. Louis, MO, China followed by counterstaining with hematoxylin. All the slides were incubated in distilled water followed by a graded series of ethanol. Finally, all the slides were processed by neutral balsam. For NKCC, the staining was performed as described above with a rabbit polyclonal antibody against NKA.

\subsection{Immunofluorescence (IF)}

After the removal of paraffin wax from tissue slides, tissue sections of the small intestine were incubated with primary antibodies against NKA, NKCC, and CA (1:100) at $4{ }^{\circ} \mathrm{C}$ overnight. Then, the slides were washed in PBS, an analogous secondary antibody was added, and sections were incubated for two hours at a normal temperature of $37^{\circ} \mathrm{C}$. Then, the sections were washed again with PBS, and 4', 6'-diamino-2-phenylidole (DAPI) was used for nuclear staining. Images of the tissues were captured directly using an Olympus microscope (BX53) and camera (Olympus DP73, Olympus Corporation Company, Tokyo, Japan). 


\subsection{Statistical Analysis}

The histomorphometry of stained tissue sections was measured by Image Pro v10 (International Scientific Community, Anaheim, CA, USA) and analyzed statistically with Graph-Pad Prism 7.0 software (IBMP Crop, USA). Available online: http://allpcworld.com/download-graphpad-prism-7-0-free/ (accessed on 17 May 2018). The results are presented as the mean \pm SEM. The statistical significance of differences between the means was also analyzed by t-test $(p<0.05)$.

\section{Results}

\subsection{Light Microscopy}

The small intestinal mucosa was composed of three main types of epithelial cells: (1) MRCs, (2) AECs, and (3) mucus secreting GCs (Figure 1). MRCs were very similar in shape and size to the AECs in the small intestine of Chinese soft-shelled turtles and were easily identified through light microscopy with high resolution.
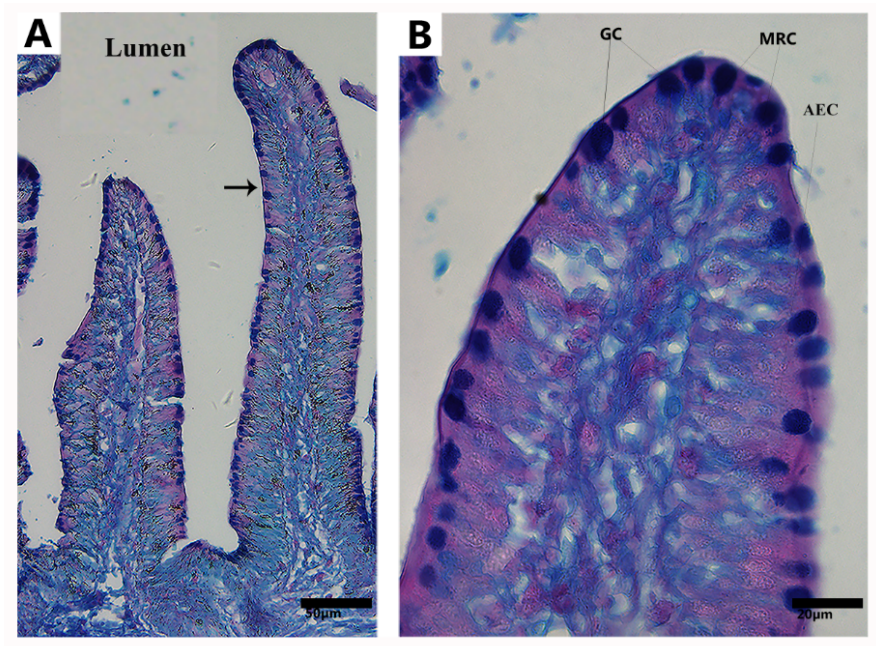

Figure 1. Light microscopy of the small intestine of Pelodiscus sinensis. Three main types of epithelial cells were present in the mucosal surface of the small intestine: mitochondria-rich cells (MRCs), absorptive epithelial cells (AECs), goblet cells (GCs), and villus (black arrow). Scale bars $=($ A) $50 \mu \mathrm{m}$ and (B) $20 \mu \mathrm{m}$.

\subsection{Transmission Electron Microcopy}

Transmission electron micrograph provided strong evidence for the existence of MRCs in the small intestine of $P$. sinensis. These cells were especially located at the upper area of the lateral border of the mucosal folds. The cytoplasm of MRCs exhibited more electron density than that of AECs and GCs (Figure 2A). Most of the cytoplasm of the MRCs was occupied by mitochondria and an extensive tubular system. However, the cytoplasm of the AECs and GCs displayed a limited number and size of mitochondria. Notably, the cytoplasm of AECs and GCs lacked an extensive tubular system. However, statistical analysis of the diameter and quantification of the mitochondria in the MRCs showed that these features were highly significant as compared with those in the AECs (Figure 2B,C). Additionally, heterogeneous morphological mitochondria, endoplasmic reticulum, and dilated Golgi complexes were found in the MRCs, as well autophagic vacuoles similar to the mitophagic profile were recorded (Figure 2A). Moreover, the extensive tubular system of MRCs was directly interposed in the mitochondria and was continuous with the basolateral membrane, resulting in a large surface area for the placement of ion-transport proteins. In highly activated MRCs, the mitochondria were well developed, and some of them had low and high electron densities (Figure 3). Additionally, inside the cytoplasm of MRCs, membrane-bound, round structures knows as the multivesicular bodies (MVBs) 
appeared with low and high electron density. These MVBs were located near the plasma membrane and secreted exosomes which were present in the lumen of the small intestine (Figures 2A and 3). The MRCs contain microvilli of various sizes, and extensive uniform interdigitation for linking with neighbor cells (AECs and GCs) was present around the lateral borders of the mucosal surface, increasing in complexity towards the base of the cells. The MRCs also played another distinct role in the maintenance of the physical barrier, as they were directly connected with AECs through tight junctions and desmosomes. In the MRCs, which showed morphological variation in mitochondria, we inferred that the increase in size was due to the fusion of mitochondria. Mitochondrial vacuolization and intermitochondrial junctions (IMJs) were observed within the MRCs (Figure 4). Furthermore, we have summarized the cytological features of MRCs, AECs, and GCs in the small intestine of Chinese soft-shelled turtles (Table 1).
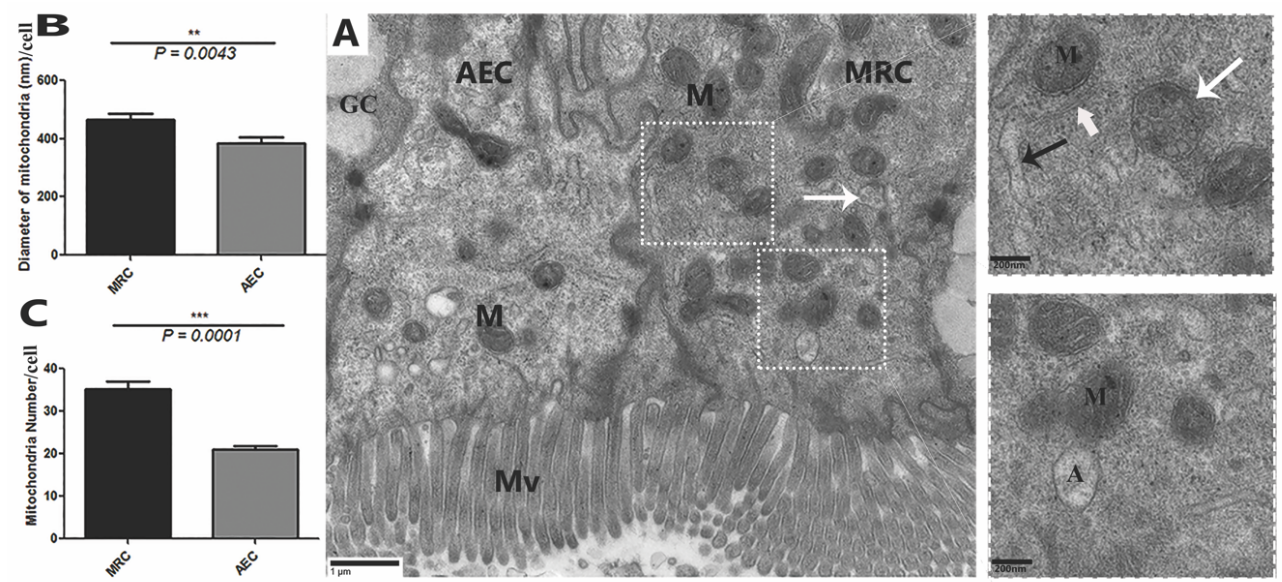

Figure 2. Transmission electron micrograph of the morphological comparison of mitochondria-rich cells (MRCs) with AECs and GCs of P. sinensis. (A) mitochondria-rich cell (MRC), absorptive epithelial cell (AEC), goblet cell (GC), mitochondria (M), autophagosome (A), microvillus (Mv), multivesicular bodies (white arrow), Golgi complex (thick white arrow) and endoplasmic reticulum (thin black arrow). (B) Quantification of the diameter of mitochondria and (C) number of mitochondria. Scale bar $=(\mathrm{A}) 1 \mu \mathrm{m}$.
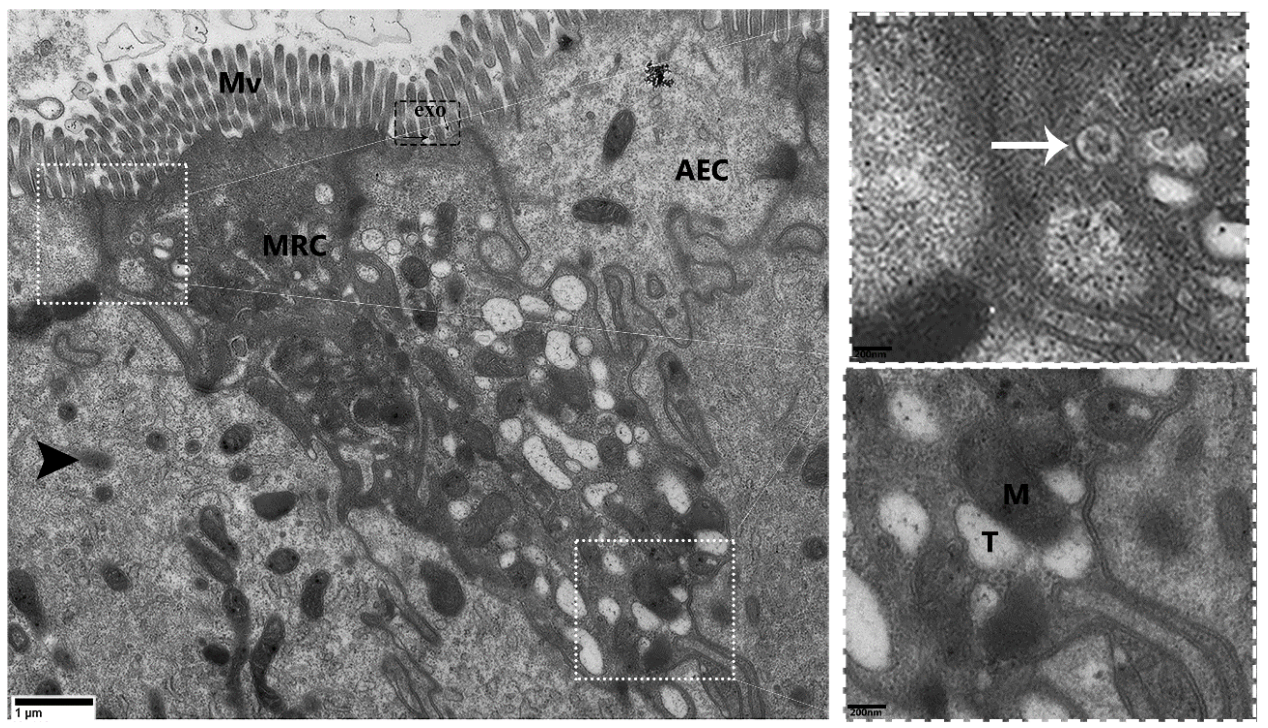

Figure 3. Transmission electron micrograph of an MRC that exhibits exosome secretion in the mucosal layer of $P$. sinensis. Mitochondria-rich cells (MRCs), absorptive epithelial cell (AEC), mitochondria (M), tubular system (T), multivesicular bodies (white arrow), exosome (exo), lysosome (black arrowhead), and microvilli (Mv). Scale bar $=1 \mu \mathrm{m}$. 

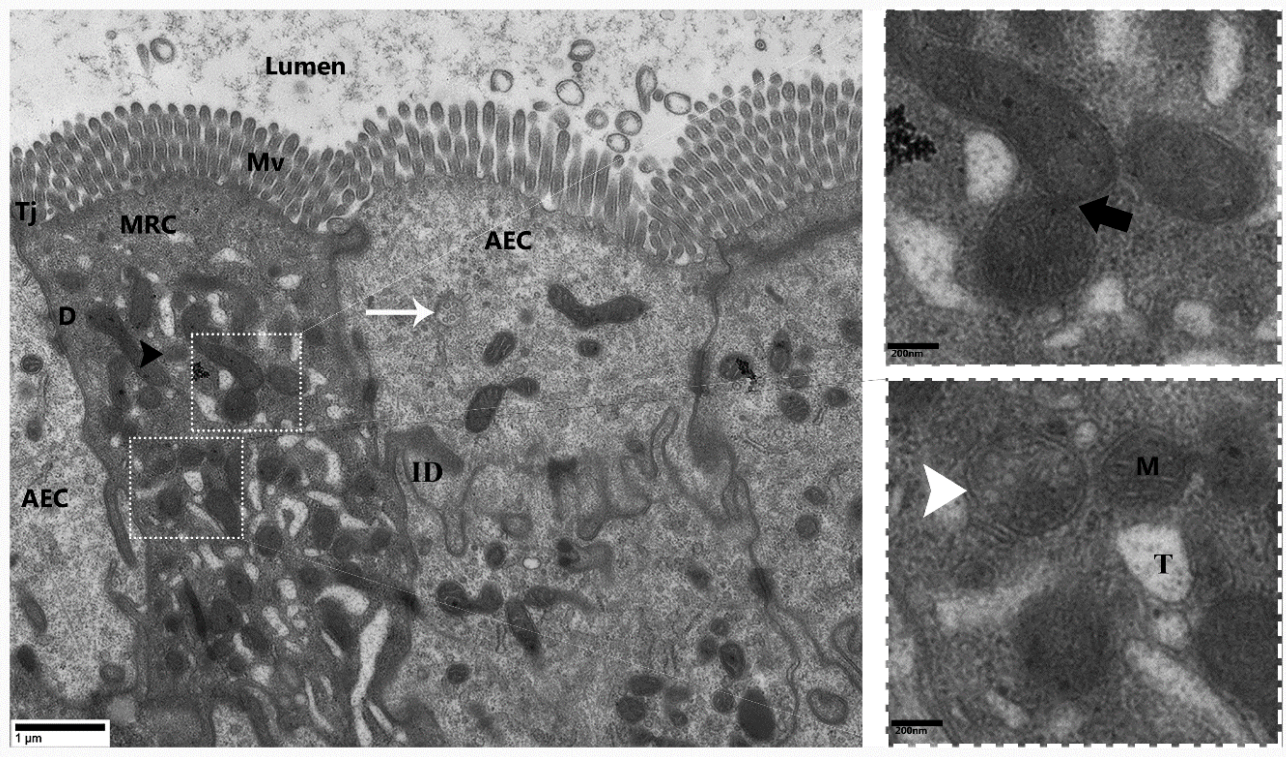

Figure 4. Transmission electron micrograph of MRC connected with the AEC in mucosal layer of P. sinensis. Mitochondria-rich cell (MRC), absorptive epithelial cell (AEC), tight junction (Tj), desmosome (D), interdigitation (ID), mitochondria (M), tubular system (T), multivesicular bodies (white arrow); vacuolization in mitochondria (white arrowhead), intermitochondrial junction (thick black arrow), lysosome (black arrowhead), microvilli (Mv). Scale bar $=1 \mu \mathrm{m}$.

Table 1. Summary of the distribution of cytological features of MRC, AEC, and GC in the mucosal layer of small intestine of Chinese soft-shelled turtle $(n=3)$.

\begin{tabular}{|c|c|c|c|}
\hline Cytological Parameters & MRC & AEC & GC \\
\hline Cytoplasmic density & +++ & + & + \\
\hline \multicolumn{4}{|c|}{ Mitochondria } \\
\hline Overall amount & +++ & + & + \\
\hline Morphological heterogeneity & ++ & ++ & ++ \\
\hline Vacuolization & + & - & - \\
\hline MVB & + & + & - \\
\hline Lysosome & + & + & + \\
\hline \multicolumn{4}{|c|}{ Tubular system (TS) } \\
\hline Dilated TS & +++ & - & - \\
\hline Small TS & ++ & - & - \\
\hline
\end{tabular}

Coding: - , absent; + , little; ++ , moderately; +++ , strongly.

\subsection{Immunohistochemistry and Immunofluorescence}

To investigate the ion transport proteins of MRCs in the mucosal surface of the small intestine, we used immunohistochemical staining to determine the expression of NKA and NKCC in MRCs. NKA and NKCC had more positive immunoreactivity at the basolateral zone of the mucosal surface of the small intestine (Figure 5A,C,D), and weak immunoreactivity was detected at the apical region of the mucosal surface (Figure 5B). Likewise, IF staining was performed to determine the cellular localization of NKA, NKCC, and CA. Immunofluorescence staining showed the strong positive immunostaining of NKA and NKCC at the basolateral region of the mucosal surface (Figure 6A,B), however, CA showed strong positive immunostaining at the apical region of the mucosal surface of the small intestine (Figure 6C). Overall, analysis of ion transport proteins by IHC and IF indicated that in the MRCs of the small intestine of $P$. sinensis the intensity of immunoreactivity increased at the basal and apical regions of the mucosal surface. 


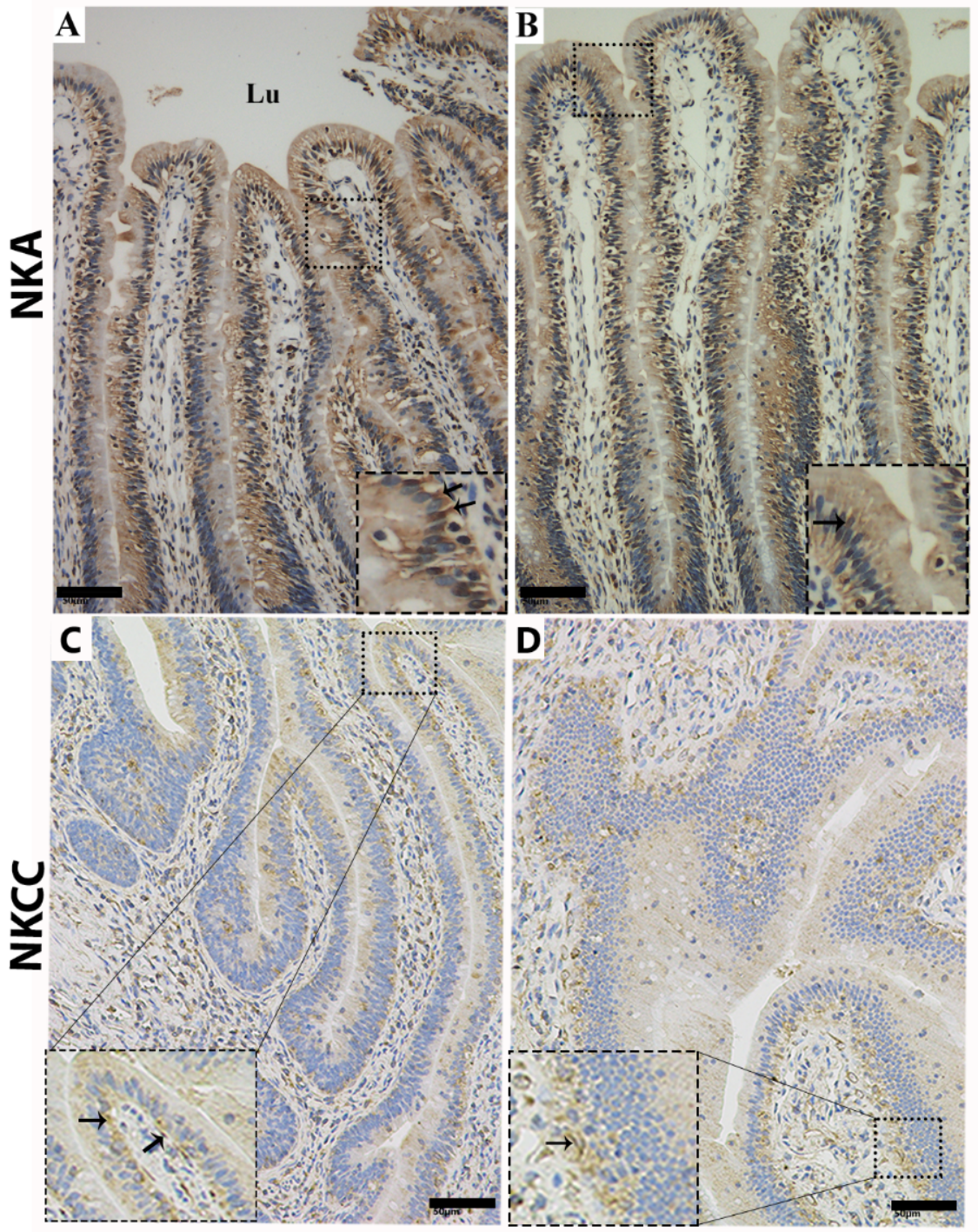

Figure 5. Immunohistochemical localization of $\mathrm{Na}^{+} / \mathrm{K}^{+}$-ATPase (NKA) and $\mathrm{Na}^{+} / \mathrm{K}^{+} / 2 \mathrm{Cl}^{-}$cotransporter (NKCC) in the mucosal surface of the small intestine of $P$. sinensis. NKA and NKCC immunoreactivity showed positive expression in the mucosal surface (black arrow). Lu: lumen. Scale bar = (A-D) $50 \mu \mathrm{m}$. 

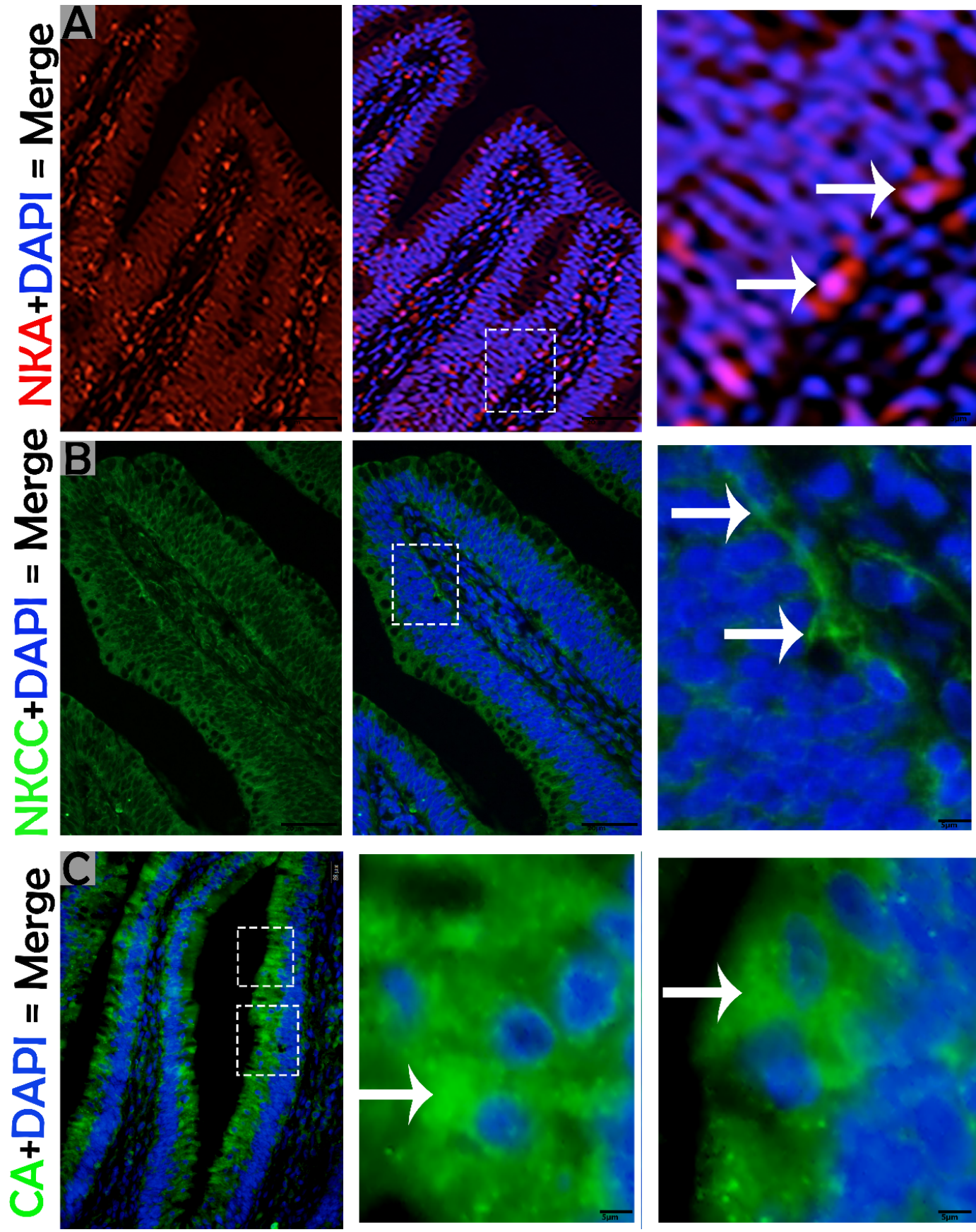

Figure 6. Immunofluorescence labeling of NKA, NKCC, and carbonic anhydrase (CA) in the small intestine of $P$. sinensis. The immunopositive localization of NKA, NKCC, and CA in the mucosal surface (white arrow). Scale bar $=(\mathbf{A}-\mathrm{C}) 20 \mu \mathrm{m}$.

\section{Discussion}

This study revealed, for the first time, the existence of MRCs within the small intestine of reptiles. Previously, these cells were revealed in the lower intestinal epithelium of chicken [8], the epithelial cells of the gills and kidney of fish [12,20,28,29], and the epidermis of the skin of amphibian [30]. Earlier studies showed that MRCs exist in clusters that form within the upper part of the mucosal fold. The cytoplasmic organelles of MRCs are very typical for ion transportation, while mitochondria and an extensive tubular system were more frequent than those in AECs [4]. In our results, MRCs were characterized by the occurrence of an abundant quantity of mitochondria with high electron 
density in the cytoplasm relative to AECs and GCs. The intestinal epithelium of the chicken contains an abundance of mitochondria, i.e., 19\% in MRCs and 10\% in AEC [31]. In contrast, in our study, mitochondria were present at 35\% in MRCs and at 20\% in AECs. In the present study, MRCs secreted different kinds of MVBs and exosomes with low and high electron density. A previous study observed that the luminal exosomes released from murine IEC4.1 help with epithelial antimicrobial protection [22], and therefore we assumed that the MRCs of turtle may perform similar immune functions.

Furthermore, these cells are differentiated by an extensive tubular system in the cytoplasm, which is distributed throughout the cytoplasm and directly interposed within the mitochondria for the placement of ion-transport proteins (NKA and NKCC). In fresh water milkfish, the tubular system of MRCs is dense along the basolateral membrane but more aggregated and very small in size around the mitochondria [28]. As shown by Luca and Towel [32], in MRCs, the tubular system increases its dispersion throughout the cytoplasm, except for the subapical region, to enlarge the surface area through which $\mathrm{Na}^{+}$and $\mathrm{K}^{+}$are transported. NKA is a main enzyme in the ion transportation of MRCs, which creates ionic and electronic gradients for ion secretion and absorption [33]. Immunocytochemistry labeling and electron microscopic observation of tilapia showed that NKA and NKCC are present in the basolateral membrane of the tubular system of MRCs [34] and similar immunofluorescence staining results for NKA and NKCC were observed in the present study. MRCs are the sites for active ammonia elimination through the ion transport proteins, NKA and NKCC [35]. In the intestinal epithelium, the activity of NKA pumps helps to achieve a substantial portion of the total energy consumption by tissue [31]. Additionally, we observed two types of mitochondria in MRCs which were distinguished by their electron density and were adjoined to form intermitochondrial junctions (IJMs). MRCs were directly connected with GCs and AECs through laterally extensive interdigitation and, consequently, developed physical barriers (desmosomes and tight junctions) for the support and maintenance of the internal milieu of the mucosal surface. MRCs are highly reactive and these cells contain carbonic anhydrase, which plays a significant role in acid-base transport for homeostasis in mammalian collecting duct MRCs [36]. The presence of CA in the branchial MRCs of fish gills indicates their involvement in the elimination of ammonia and in the active elimination of $\mathrm{Cl}^{-}$[37]. MRCs proliferate to increase the ion regulatory capacity of the fish gills in response to osmotic challenges. Colisalalia and Trichigastertrichopterus are both primary freshwater fishes with labyrinths in their gill chambers to enhance air breathing [29]. Chinese soft-shelled turtles hibernate in water for a long time and, consequently, require more ATP utilization for their continued existence. In addition, we observed autophagic vacuoles in MRCs and electron dense contents, similar to autophagy. Intestinal epithelial cell autophagy protects against tissue invasion by both opportunistically hostile commensals and invasive intestinal pathogens [38]. In a previous report, autophagy maintained cellular function and was involved in the elimination of damaged mitochondria [39]. In the current study, cristealysis and matrix vacuolization of mitochondria in MRCs were observed, and the mitochondria appeared as fluid-filled spherical vacuoles. Meanwhile, the endoplasmic reticulum and dilated Golgi complex were spread around the mitochondria. Many studies have demonstrated the contribution of the endoplasmic reticulum (ER) to autophagy vacuole formation and the interchange of molecules with mitochondria for the maintenance of cellular homeostasis. Mitophagy may be associated with mitochondrial fission by separating functional mitochondria from the damaged portion [39]. Additionally, after nitrite treatment, the numbers of mitochondria-rich cells decreased, and swelling of the endoplasmic reticulum and vacuolization of the mitochondria occurred inside the mitochondria-rich cells [19].

\section{Conclusions}

In this study, we provided new insight regarding the existence of MRCs in the small intestine of Chinese soft-shelled turtles. These cells are very distinct in morphology and ultrastructure, and their electron density clearly separates them from the AECs and GCs. A schematic diagram of the morphology and functional activity of MRCs in the small intestine of P. sinensis is presented in (Figure 7). This study 
highlights the significance of the ultrastructure and the different ion transport proteins of MRCs in the small intestine. However, the immunological role of MRCs in the intestine needs more exploration.

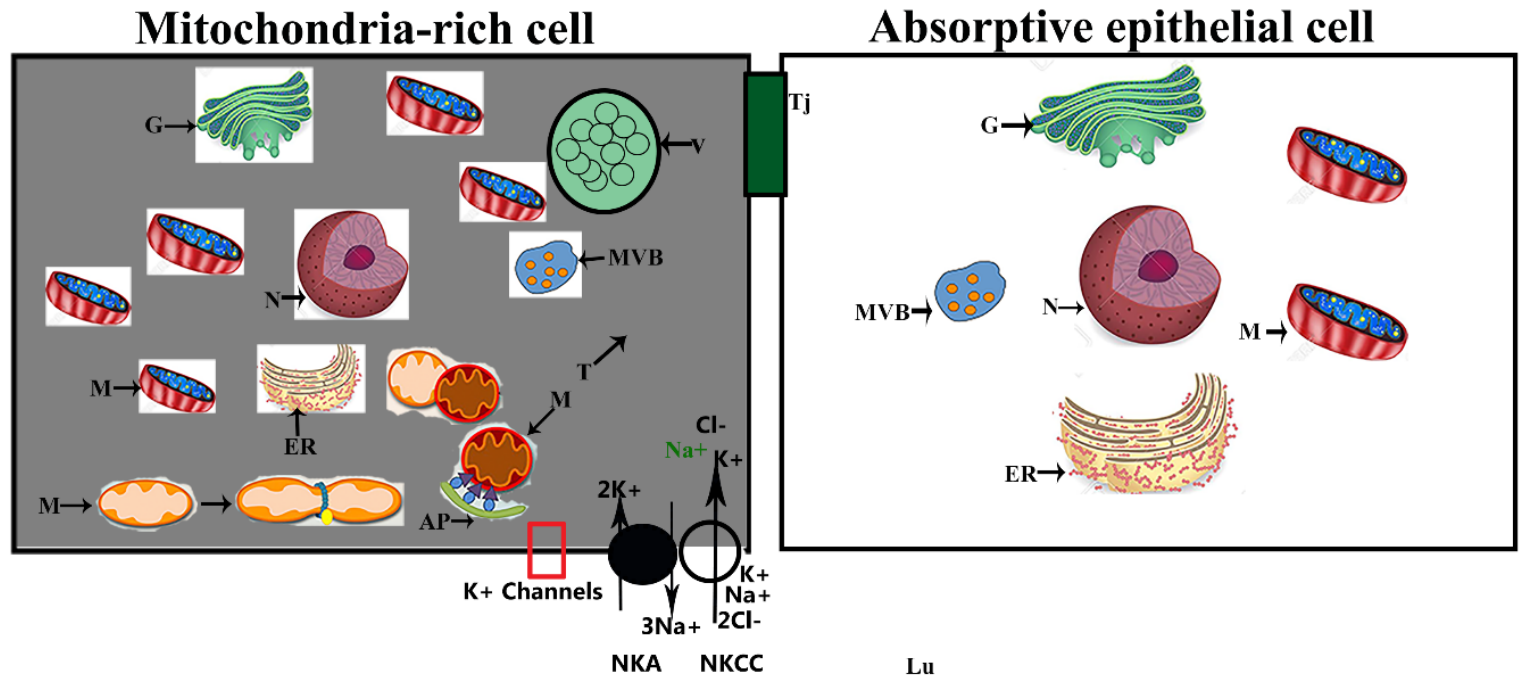

Figure 7. Schematic diagram of morphology and functional activity of MRC in the small intestine of $P$. sinensis. Dense cytoplasm MRCs contain greater numbers of mitochondria and a tubular system compared to absorptive epithelial cells. $\mathrm{Cl}^{-}$enters $\mathrm{MRC}$ s via a $\mathrm{Na}^{+} / \mathrm{K}^{+} / 2 \mathrm{Cl}^{-}$cotransporter (NKCC) driven by the $\mathrm{Na}^{+}$gradient, which is maintained by $\mathrm{Na}^{+} / \mathrm{K}^{+}{ }_{-}$ATPase (NKA). The red rectangle highlights the potassium channels required in this process. Nucleus $(\mathrm{N})$, mitochondria (M), endoplasmic reticulum (ER), autophagosome (AP), tubular system (T), multivesicular bodies (MVB), vacuolization $(\mathrm{V})$, tight junction $(\mathrm{Tj})$, and Golgi complex $(\mathrm{G})$.

Author Contributions: W.A.V., Q.C., Y.L., X.B. and M.X. designed and conducted the experiments; W.A.V., Y.H., A.H., N.S.G. and L.Y. analyzed the data; and W.A.V. I.T., Q.C. and P.Y. wrote and revised the paper.

Funding: Grants from the National Natural Science Foundation of China (grant numbers: 31872433 and 31672505), the Priority Academic Program Development of Jiangsu Higher Education Institutions, and the PR-307 China and Postgraduate Research and Practice Innovation Program of Jiangsu Province supported the present research.

Conflicts of Interest: No potential conflicts of interest were disclosed.

\section{References}

1. Putterill, J.; Soley, J. General Morphology of the oral cavity of the Nile crocodile, Crocodylus niloticus (Laurenti, 1768). I. Palate and gingivae. Onderst. J. Vet. Res. 2003, 70, 281-297. [CrossRef]

2. Parsons, T.S.; Cameron, J.E. Internal relief of the digestive tract. Biol. Rept. 1977, 6, 159-223.

3. Ghishan, F.K.; Kiela, P.R. Small intestinal ion transport. Curr. Opin. Gastroenterol. 2012, 28, 130. [CrossRef] [PubMed]

4. Elbrønd, V.S.; Dantzer, V.; Skadhauge, E. Differences in epithelial morphology correlate to Na+-transport: A study of the proximal, mid, and distal regions of the coprodeum from hens on high and low $\mathrm{NaCl}$ diet. J. Morphol. 1999, 239, 75-86. [CrossRef]

5. Ura, K.; Soyano, K.; Omoto, N.; Adachi, S.; Yamauchi, K. Localization of Na+, K+-ATPase in tissues of rabbit and teleosts using an antiserum directed against a partial sequence of the $\alpha$-subunit. Zool. Sci. 1996, 13, 219-227. [CrossRef] [PubMed]

6. Shiraishi, K.; Hiroi, J.; Kaneko, T.; Matsuda, M.; Hirano, T.; Mori, T. In vitro effects of environmental salinity and cortisol on chloride cell differentiation in embryos of Mozambique tilapia, Oreochromis mossambicus, measured using a newly developed 'yolk-ball'incubation system. J. Exp. Biol. 2001, 204, 1883-1888.

7. Nebel, C.; Romestand, B.; Nègre-Sadargues, G.; Grousset, E.; Aujoulat, F.; Bacal, J.; Bonhomme, F.; Charmantier, G. Differential freshwater adaptation in juvenile sea-bass Dicentrarchus labrax: Involvement of gills and urinary system. J. Exp. Biol. 2005, 208, 3859-3871. [CrossRef] 
8. Elbrønd, V.S.; Jones, C.J.; Skadhauge, E. Localization, morphology and function of the mitochondria-rich cells in relation to transepithelial Na+-transport in chicken lower intestine (coprodeum). Comp. Biochem. Physiol. Part A Mol. Integr. Physiol. 2004, 137, 683-696. [CrossRef] [PubMed]

9. Bao,H.; Chen, Q.; Su, Z.; Qin, J.; Xu, C.; Arencibia, A.; Rodríguez-Ponce, E.; Jaber, J. The study of microanatomy of intestinal epithelium in the Chinese soft-shelled turtle (Pelodiscus sinensis). Iran. J. Vet. Res. 2017, 18, 282. [PubMed]

10. Keys, A.; Willmer, E. 'Chloride secreting cells' in the gills of fishes, with special reference to the common eel. J. Physiol. 1932, 76, 368-378. [CrossRef]

11. Kaneko, T.; Watanabe, S.; Lee, K.M. Functional Morphology of Mitochondrion-Rich Cells in Euryhaline and Stenohaline Teleosts; Citeseer: Tokyo, Japan, 2008; pp. 1-62.

12. Jonz, M.G.; Nurse, C.A. Epithelial mitochondria-rich cells and associated innervation in adult and developing zebrafish. J. Comp. Neurol. 2006, 497, 817-832. [CrossRef]

13. Foskett, J.K.; Scheffey, C. The chloride cell: Definitive identification as the salt-secretory cell in teleosts. Science 1982, 215, 164-166. [CrossRef]

14. Karnaky, K.J., Jr. Structure and function of the chloride cell of Fundulus heteroclitus and other teleosts. Am. Zool. 1986, 26, 209-224. [CrossRef]

15. Perry, S.F. The chloride cell: Structure and function in the gills of freshwater fishes. Annu. Rev. Plant Physiol. 1997, 59, 325-347. [CrossRef]

16. Devuyst, O.; Beaujean, V.; Crabbé, J. Effects of environmental conditions on mitochondrial-rich cell density and chloride transport in toad skin. Pflügers Arch. 1991, 417, 577-581. [CrossRef]

17. Perry, S.F. Relationships between branchial chloride cells and gas transfer in freshwater fish. Comp. Biochem. Physiol. Part A Mol. Integr. Physiol. 1998, 119, 9-16. [CrossRef]

18. Evans, D.H.; Piermarini, P.M.; Potts, W. Ionic transport in the fish gill epithelium. J. Exp. Zool. 1999, 283, 641-652. [CrossRef]

19. COSTA, O.T.D.; Ramos, C.A.; Duncan, W.P.; Lameiras, J.L.; Fernandes, M.N. Mitochondria-rich cells changes induced by nitrite exposure in tambaqui (Colossoma macropomum Cuvier, 1818). An. Acad. Bras. Ciênc. 2017, 89, 965-972. [CrossRef]

20. Carmo, T.L.; Azevedo, V.C.; Siqueira, P.R.; Galvão, T.D.; Santos, F.A.; Martinez, C.B.; Appoloni, C.R.; Fernandes, M.N. Mitochondria-rich cells adjustments and ionic balance in the Neotropical fish Prochilodus lineatus exposed to titanium dioxide nanoparticles. Aquat. Toxicol. 2018, 200, 168-177. [CrossRef]

21. Tang, X.; Zhang, H. Cytochemical studies on the formation of multivesicular bodies in Leydig cells. Shiyan J. Biol. 1990, 23, 453-463.

22. Hu, G.; Gong, A.-Y.; Roth, A.L.; Huang, B.Q.; Ward, H.D.; Zhu, G.; LaRusso, N.F.; Hanson, N.D.; Chen, X.-M. Release of luminal exosomes contributes to TLR4-mediated epithelial antimicrobial defense. PLoS Pathog. 2013, 9, e1003261. [CrossRef]

23. Hwang, P.-P.; Lee, T.-H.; Weng, C.-F.; Fang, M.-J.; Cho, G.-Y. Presence of Na-K-ATPase in mitochondria-rich cells in the yolk-sac epithelium of larvae of the teleost Oreochromis mossambicus. Physiol. Biochem. Zool. 1999, 72, 138-144. [CrossRef] [PubMed]

24. McBride, B.; Kelly, J. Energy cost of absorption and metabolism in the ruminant gastrointestinal tract and liver: A review. J. Anim. Sci. 1990, 68, 2997-3010. [CrossRef] [PubMed]

25. Mallegol, J.; Van Niel, G.; Lebreton, C.; Lepelletier, Y.; Candalh, C.; Dugave, C.; Heath, J.K.; Raposo, G.; Cerf-Bensussan, N.; Heyman, M. T84-intestinal epithelial exosomes bear MHC class II/peptide complexes potentiating antigen presentation by dendritic cells. Gastroenterology 2007, 132, 1866-1876. [CrossRef] [PubMed]

26. Cocucci, E.; Racchetti, G.; Meldolesi, J. Shedding microvesicles: Artefacts no more. Trends Cell Boil. 2009, 19, 43-51. [CrossRef] [PubMed]

27. Schreiber, A.M.; Specker, J.L. Metamorphosis in the summer flounder Paralichthys dentatus: Changes in gill mitochondria-rich cells. J. Exp. Biol. 1999, 202, 2475-2484.

28. Yang, S.H.; Tsai, J.D.; Kang, C.K.; Yang, W.K.; Kung, H.N.; Lee, T.H. The ultrastructural characterization of mitochondria-rich cells as a response to variations in salinity in two types of teleostean pseudobranch: Milkfish (Chanos chanos) and Mozambique tilapia (Oreochromis mossambicus). J. Morphol. 2017, 278, 390-402. [CrossRef] 
29. Lin, H.-C.; Sung, W.-T. The distribution of mitochondria-rich cells in the gills of air-breathing fishes. Phys. Biol. Zool. 2003, 76, 215-228. [CrossRef]

30. Kanakasabapathy, I.; Rajakumari, S.J.; Subramani, S.; Rao, P.J. Mitochondria-rich Cells in South Indian Green Pond Frog (euphlyctishexadactylus)-A Light and Electron Microscopic Study. J. Anat. Soc. India 2009, 58, 126-129.

31. Cramp, R.L.; Kayes, S.M.; Meyer, E.A.; Franklin, C.E. Ups and downs of intestinal function with prolonged fasting during aestivation in the burrowing frog, Cyclorana alboguttata. J. Exp. Biol. 2009, 212, 3656-3663. [CrossRef]

32. Lucu, Č.; Towle, D.W. Na++ K+-ATPase in gills of aquatic crustacea. Comp. Biochem. Physiol. Part A Mol. Integr. Physiol. 2003, 135, 195-214. [CrossRef]

33. Wood, C.M.; Shuttleworth, T.J. Cellular and Molecular Approaches to Fish Ionic Regulation; Academic Press: New York, NY, USA, 1995; Volume 14, p. 352.

34. Klöhn, P.C.; Castro-Seoane, R.; Collinge, J. Exosome release from infected dendritic cells: A clue for a fast spread of prions in the periphery? J. Infect. 2013, 67, 359-368. [CrossRef]

35. Johnstone, R.M. Exosomes biological significance: A concise review. Blood Cells Mol. Dis. 2006, 36, 315-321. [CrossRef]

36. Fritsche, C.; Kleinman, J.; Bain, J.; Heinen, R.; Riley, D. Carbonic anhydrase in turtle bladder mitochondrial-rich luminal and subluminal cells. Am. J. Physiol. Renal Physiol. 1991, 260, F431-F442. [CrossRef]

37. Lai, K.P.; Li, J.-W.; Gu, J.; Chan, T.-F.; Tse, W.K.F.; Wong, C.K.C. Transcriptomic analysis reveals specific osmoregulatory adaptive responses in gill mitochondria-rich cells and pavement cells of the Japanese eel. BMC Genom. 2015, 16, 1072. [CrossRef]

38. Benjamin, J.L.; Sumpter, R., Jr.; Levine, B.; Hooper, L.V. Intestinal epithelial autophagy is essential for host defense against invasive bacteria. Cell Host Microbe 2013, 13, 723-734. [CrossRef]

39. Ferreira, F.F.; Nazari, E.M.; Müller, Y.M. MeHg Causes Ultrastructural Changes in Mitochondria and Autophagy in the Spinal Cord Cells of Chicken Embryo. J. Toxicol. 2018, 2018, 12. [CrossRef]

(C) 2019 by the authors. Licensee MDPI, Basel, Switzerland. This article is an open access article distributed under the terms and conditions of the Creative Commons Attribution (CC BY) license (http://creativecommons.org/licenses/by/4.0/). 